Erratum

\title{
Erratum to: Cerebral Microcirculation and Oxygen Tension in the Human Secondary Cortex
}

\author{
A. A. Linninger, ${ }^{1}$ I. G. Gould,${ }^{1}$ T. Marinnan, ${ }^{2}$ C.-Y. Hsu, ${ }^{1}$ M. Chojecki, ${ }^{1}$ and A. Alaraj ${ }^{3}$ \\ ${ }^{1}$ Department of Bioengineering, University of Illinois at Chicago, 851 S. Morgan St, 218 SEO, M/C 063, Chicago, IL 60607- \\ 7000, USA; ${ }^{2}$ Department of Computer Science, University of Illinois at Chicago, Chicago, IL, USA; and ${ }^{3}$ University of Illinois at \\ Chicago, School of Medicine, Chicago, IL, USA
}

\section{Erratum to: Annals of Biomedical Engineering (2013) 41(11):2264-2284 DOI 10.1007/s10439-013-0828-0}

The caption for Fig. 6 is listed under Fig. 7, the caption for Fig. 7 is listed under Fig. 8, and the caption for Fig. 8 is listed under Fig. 6.

Address correspondence to A. A. Linninger, Department of Bioengineering, University of Illinois at Chicago, $851 \mathrm{~S}$. Morgan St, 218 SEO, M/C 063, Chicago, IL 60607-7000, USA. Electronic mail: linninge@uic.edu

The online version of the original article can be found under doi: 10.1007/s10439-013-0828-0. 